\title{
O grau de competência em comunicação audiovisual entre os cidadãos da Andaluzia (Espanha) $)^{1}$
}

Ignacio Aguaded Catedrático da Universidade de Huelva (Espanha), presidente do Grupo Comunicar e editor da Revista Cientifica Comunicar.

E-mail: aguade@uhu.es

Rocío Cruz-Díaz

Professora Contratada da Universidade Pablo de Olavide (Sevilha). Coordenadora Acadêmica do programa "Aula Abierta de Mayores", da Universidade e membro do Grupo Comunicar.

E-mail: mrcrudia@upo.es

Resumo: A competência em comunicação audiovisual entre os andaluzes passa, na atualidade, por importantes carências e graves demandas, tanto na disposição para interpretar mensagens audiovisuais de modo reflexivo e crítico, quanto na capacidade de expressão por meio da linguagem audiovisual com um mínimo de correção e criatividade. Este estudo aborda de forma geral um processo de planejamento, elaboração, validação e aplicação de um questionário sobre a competência audiovisual na população andaluza em função das variáveis gênero, idade, nível de escolaridade e província. Os dados extraídos fazem parte de um estudo de alcance estatal em toda a Espanha.

Palavras-chave: comunicação audiovisual; competência; educação; jovens; adultos; idosos.
Abstract: The competence in audiovisual communication between the people from Andalusia is currently going through significant shortages and serious demands, both in the readiness to interpret audiovisual messages in a reflexive and critical way, and in the ability to express using an audiovisual language with correction and creativity. This study addresses, in general, a process of planning, validation and implementation of a questionnaire on audiovisual competences of the citizens from Andalusia considering the variables of gender, age, education and province. The information collected is part of a state scope in throughout Spain.

Keywords: audiovisual communication; competence; education; young people; adults; elderly population.

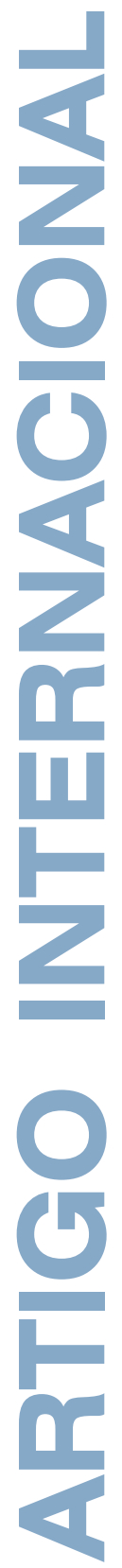

Recebido: 03/10/2013

Aprovado: 03/12/2013

1. Este estudo se produziu no âmbito da Chamada de Projetos I+D do Ministério Espanhol de Economia e Competitividade, com o código EDU201021395-C03-03, intitulado: "O ensino obrigatório diante da competência em comunicação audiovisual em um ambiente 


\section{O ESTUDO}

O estado de abandono no qual se encontra a educação na comunicação audiovisual fica evidente, entre outros dados, pela carência que durante décadas padeceu o sistema educacional em particular e a sociedade em geral, de uma adequada definição (precisa e consensual) de tudo aquilo que pressupõe mostrar destrezas e competências diante do "audiovisual e comunicativo" e, consequentemente, pela ausência de ferramentas que nos permitam avaliar e quantificar o nível de competência do indivíduo, tal como afirma o professor Ferrés ${ }^{2}$ em seu artigo "Competência em comunicação audiovisual: dimensões e indicadores".

Em 2002, o Conselho Audiovisual da Catalunha abordou com especial atenção o estudo das necessidades de ação para melhorar as destrezas básicas dos cidadãos da Catalunha em relação aos meios de comunicação, enfatizando a necessidade de uma alfabetização digital e maior formação em línguas estrangeiras. O desenvolvimento eficaz das destrezas comunicativas pressupõe que o indivíduo tenha adquirido competência em comunicação audiovisual, entendida como "a capacidade de um indivíduo para interpretar e analisar as imagens e mensagens audiovisuais e para se expressar com uma correção mínima no âmbito comunicativo"3.

Com o objetivo de aprofundar em nível estatal o estudo da competência audiovisual dos cidadãos espanhóis, um grupo de especialistas liderado por pesquisadores de experiência reconhecida - como I. Aguaded, R. Aparici, J. Ferrés, A. García-Matilla etc. - foi responsável por uma prática pioneira em nível nacional e internacional sobre o âmbito da comunicação audiovisual. Em um primeiro momento, aprofundou-se a definição de "Competência em Comunicação Audiovisual”. Posteriormente, uma vez definido o conceito, o estudo consistiu na elaboração de um questionário como instrumento básico para medir o grau de competência audiovisual da população espanhola. O projeto estendeu sua aplicação para 17 universidades, correspondentes a cada

digital" e do Projeto de Pesquisa de Excelência da Junta da Andaluzia EJ-5823-2010, denominado "A competência audiovisual dos cidadãos andaluzes. Estratégicas de alfabetização para os meios de comunicação na sociedade do lazer digital".

2. FERRÉS, Joan. La competencia en comunicación audiovisual: dimensiones e indicadores. [Competência em comunicação audiovisual: dimensões e indicadores]. Comunicar, 29, XV, 2007, p. 100-107.

3. Idem, p. 102. uma das comunidades autônomas da Espanha. Serviu de referente conceitual para os pesquisadores o documento publicado pelo Conselho do Audiovisual da Catalunha [Consell de l'Audiovisual de Catalunya] (CAC) (2007): "Competência em comunicação audiovisual: proposta articulada de dimensões e indicadores". O projeto teve apoio do CAC através da Universidade Pompeu Fabra de Barcelona (Espanha).

A equipe de pesquisadores elaborou um questionário que, posteriormente, foi validado nas Comunidades Autônomas da Espanha, por cada uma das universidades participantes. Finalmente, realizou-se o trabalho de campo abordado pela equipe de pesquisadores dirigida pelo Dr. Ignacio Aguaded, aplicando os questionários, processando os dados e pontuando os resultados obtidos - concretamente, os resultados da Comunidade Autônoma Andaluza.

Nessa fase do estudo global, utilizou-se uma metodologia científica de caráter quantitativo. Para detectar o nível de competência em algumas dimensões, 
recorreu-se a uma enquete com perguntas fechadas (que podem incluir respostas escaladas) e perguntas abertas. Para avaliar o nível de competência em outros âmbitos foi preciso recorrer, em uma segunda fase, a técnicas de caráter qualitativo, como os grupos focais (focus group) e as entrevistas aprofundadas.

\section{OS OBJETIVOS}

Entre outros aspectos, a pesquisa pretende contribuir para potencializar o desenvolvimento de uma política de alfabetização audiovisual na Espanha e a perfilar os objetivos, conteúdos, procedimentos e atitudes necessárias em cada âmbito.

Ao abordar o estudo de temáticas como a Educação em Comunicação Audiovisual, fica evidente a ausência de avaliações sobre o grau de competência das pessoas nesse âmbito. Os pesquisadores afirmam que a eficácia dos processos de ensino-aprendizagem está condicionada, em grande parte, pela eficiência dos sistemas de avaliação por eles incorporados. Para Joan Ferrés, J. Ignacio Aguaded, Agustín García e suas equipes de especialistas, poder-se-ia falar do estabelecimento de um círculo vicioso: não se avaliam as competências em comunicação audiovisual porque elas não são ensinadas, desta forma, provavelmente não são ensinadas porque, já que não são avaliadas, não se tem consciência das demandas existentes no entorno.

Entre os objetivos gerais: medir o nível de competência em comunicação audiovisual das pessoas (não profissionais), a fim de certificar, se for o caso, a necessidade de uma educação em comunicação audiovisual; descobrir aquelas dimensões sobre as quais é mais urgente atuar.

Entre os objetivos específicos: definir o conceito de competência em comunicação audiovisual. Avaliar o grau de competência audiovisual e sua eficácia nos processos de ensino-aprendizagem; desenvolver um sistema de avaliação eficaz que proporcione uma definição precisa de conhecimentos, habilidades e atitudes que poderiam ser desenvolvidas para considerar uma pessoa competente por um âmbito acadêmico em comunicação audiovisual.

\section{A AMOSTRAGEM}

A amostragem de cidadãos andaluzes a partir da qual se chegou aos resultados apresentados neste artigo foi formada por 598 pessoas de gênero, idade, nível de escolaridade e províncias andaluzas diferentes. O objetivo é chegar a resultados que sejam representativos da sociedade andaluza em seu conjunto. Há uma porcentagem ligeiramente superior de mulheres (343 ou 57,4\%) que de homens (251 ou 42,0\%). A maioria dos entrevistados - 367 ou $61,4 \%$ - tem entre 25 e 59 anos, enquanto o segundo grupo mais numeroso é o de jovens de 16 a 24 anos (130 ou 21,7\%). Finalmente, o de pessoas de mais de 65 anos, que representa 81 ou $13,5 \%$. 
Quanto ao nível de escolaridade dos entrevistados, a maioria $(45,4 \%)$ tem ensino secundário, seguido dos que têm nível universitário $(32,4 \%)$ e primário (17,2\%). Por último, 4,9\% dos entrevistados não têm formação escolar.

\section{O QUESTIONÁRIO}

O instrumento selecionado para a coleta de informações sobre a Competência Audiovisual foi o questionário. Para alcançar o objetivo de elaborar uma definição do conceito de competência audiovisual delimitaram-se os âmbitos de incidência da competência e as dimensões que é preciso alcançar. A pesquisa diferencia as seguintes dimensões: a linguagem, a tecnologia, os processos de produção e programação, a ideologia e os valores, a recepção e as audiências, a estética.

A partir dessa relação de dimensões elaborou-se a "Enquete de avaliação de nível de competência audiovisual” dos cidadãos e cidadãs espanholas. O projeto da pesquisa proporciona uma extensa descrição das características que são objeto do estudo e uma comparação dos diferentes grupos de idade, nível de escolaridade e gênero. Consta de 30 itens que combinam perguntas fechadas com outras semiestruturadas e abertas. As variáveis trabalhadas foram: gênero (homens/mulheres); idade (de 16 a 24 anos, de 25 a 59 anos, de 60 em diante); nível de escolaridade (sem estudos ou apenas ensino primário, secundário e superior).

$\mathrm{Na}$ Comunidade Autônoma Andaluza, os pesquisadores e professores membros das respectivas universidades andaluzas coordenadas pela Universidade de Huelva e pesquisadores do Grupo Comunicar foram responsáveis pela aplicação do questionário.

\section{RESULTADOS}

Estamos avaliando o nível de competência em uma matéria (comunicação audiovisual) para a qual a maior parte dos cidadãos não teve, ao longo da vida, a menor preparação. Era lógico, consequentemente, um nível de acerto bastante baixo para algumas questões. Inclusive, admite-se que podia ocorrer algum campo no qual nem mesmo os profissionais da comunicação audiovisual ou outros especialistas fossem suficientemente competentes. Estamos nos referindo ao conhecimento dos mecanismos de funcionamento da dimensão emocional (ideologia e valores).

Os dados estatísticos básicos obtidos foram: as respostas válidas e as descartadas, a frequência (com média, mediana e moda), a porcentagem, a porcentagem válida e a porcentagem acumulada. Esses dados são registrados, inicialmente, em relação a todas e a cada uma das 30 perguntas que compõem o questionário; posteriormente, constam os dados básicos para cada uma das dimensões em que está estruturada a competência em comunicação audiovisual; finalmente, os dados básicos para o conjunto do questionário que foram tratados com o programa estatístico SPSS. 
A configuração da amostragem na Andaluzia, como nas demais comunidades autônomas espanholas, esteve sujeita a três variáveis: a idade, o gênero e o nível de escolaridade. Parecia evidente supor diferenças quanto à idade, que poderiam ser justificadas pela formação acadêmica (Sistema Educacional Espanhol) recebida em diferentes épocas quanto à sensibilidade a tais temas. O nível de estudos era também, a priori, um elemento interessante a ser considerado, porque significaria que num nível mais alto de educação formal correspondem mais possibilidades de mostrar uma atitude madura e crítica diante dos meios de comunicação. A maioria das pessoas entrevistadas (49,7\%) afirma não ter recebido jamais nenhum tipo de formação em comunicação audiovisual. $\mathrm{Na}$ Andaluzia, a formação audiovisual não faz nem nunca fez parte do currículo escolar. Os pesquisadores ficaram atentos ao grau de autoformação em relação ao audiovisual que os entrevistados possam ter tido. Isso poderia explicar que mais de $20 \%$ (uma proporção bastante elevada) tenham respondido que dispõem de muita informação. Talvez, em tais casos, os entrevistados façam referência a cursos de informática e/ou tratamento de imagens no computador etc.

O conjunto de 30 itens do questionário totalizam 100 pontos quanto ao grau de competência em comunicação audiovisual dos andaluzes maiores de 16 anos. A atribuição ${ }^{4}$ dessa pontuação foi feita a partir dos conhecimentos sobre "estética" (15 pontos); "ideologia e valores das mensagens" (25 pontos); "processo de recepção e questões relacionadas à audiência" (13 pontos); "rotinas de produtores e programadores" (12 pontos) e "questões tecnológicas" (15 pontos). A média é de 23,38\% sobre 100, com um desvio padrão de 12 pontos; alcançando $97 \%$ dos entrevistados valores bastante negativos. A pontuação máxima, a ser descartada por apenas uma pessoa, foi de 69 pontos, ainda assim uma pontuação bastante deficiente. A variável província em que reside recebe pontuações bem negativas, que vão de $100 \%$ a $96 \%$. Quanto ao gênero, não são perceptíveis diferenças entre homens e mulheres (em torno de 98\%).

\section{CONCLUSÃO}

Os dados prévios nos permitem concluir que o grau de competência em comunicação audiovisual na Andaluzia é extremamente baixo com graves carências na capacidade de interpretar mensagens audiovisuais de maneira crítica e reflexiva ${ }^{5}$. As necessidades de formação afetam a todas as dimensões definidas pelos especialistas: estética, linguagem, ideologia e valores, tecnologia, produção e programação, recepção e audiência ${ }^{6}$. Os pesquisadores recomendam que sejam atendidas objetivamente as necessidades e carências dos andaluzes, incentivando a alfabetização para a mídia de jovens e adultos. São estes últimos os que apresentam as maiores carências nas competências de comunicação audiovisual.

Uma proposta destacada é a introdução nos centros escolares andaluzes (de educação infantil, primária e secundária) de uma disciplina Educação para os meios de comunicação ou educação em comunicação audiovisual, como já foi proposto
4. AGUADED, Ignacio. El grado de competencia mediática en la ciudadanía andaluza. [O grau de competência para os meios de comunicação entre os cidadãos andaluzes]. Huelva: Grupo Comunicar Ediciones/Ágora, Universidad de Huelva, 2011. p. 93. Disponível em: <http://issuu.com/ grupo-comunicar/docs/ competencia-mediatica? mode $=$ window\&backgro undColor $=\% 23222222>$. Acesso em: 29 out. 2011.

5. Idem, p. 99. 6. FERRÉS, Joan, op. cit., ibidem. 
em outras comunidades da Espanha. Neste sentido, chama a atenção quanto aos valores (mais positivos) sobre o grau de competência em relação ao nível de escolaridade.

\section{REFERÊNCIAS}

AGUADED, Ignacio. El grado de competencia mediática en la ciudadanía andaluza. [O grau de competência para os meios de comunicação entre os cidadãos andaluzes]. Huelva: Grupo Comunicar Ediciones/Ágora, Universidad de Huelva, 2011, p. 93. Disponível em: <http://issuu.com/grupo-comunicar/ docs $/$ competencia-mediatica? mode=window\&backgroundColor $=\%$ 23222222 $>$. Acesso em: 29 out. 2011.

AGUADED, J. Ignacio. Media Proficiency - An Educational Initiative that Cannot Wait. [Proficiência para os meios de comunicação, uma iniciativa educacional que não pode esperar.] Comunicar, 39, 07-08, 2012 (DOI: 10.3916/C39-2012-01-01).

CONSELL DE L'AUDIOVISUAL DE CATALUNYA. La competència en comunicación audiovisual: proposta articulada de dimensions i indicadors. [A competência em comunicação audiovisual: proposta articulada de dimensões e indicadores.] Barcelona: CAC, 2007.

CORBETTA, Piergiorgio. Metodología y técnicas de investigación social. [Metodologia e técnicas de pesquisa social.] Madri: McGraw-Hill, 2003.

FERRÉS, Joan. La competencia en comunicación audiovisual: dimensiones e indicadores. [Competência em comunicação audiovisual: dimensões e indicadores.] Comunicar, 29, XV, 2007.

PERUJO, Francisco. El investigador en su laberinto. [O investigador em seu labirinto]. Sevilha: Comunicación Social, 2009. 